\title{
SSinteza
}

Impact of Internet on Business Activities in Serbia and Worldwide

Uticaj Interneta na poslovanje u Srbiji i svetu

DOI: 10.15308/SINTEZA-2014-180-185

\section{PRIMENA INTERNETA U SAVREMENOM BANKARSKOM I BERZANSKOM POSLOVANJU}

\author{
Zoran Jović \\ Univerzitet Singidunum, Poslovni fakultet u Valjevu, Srbija
}

\begin{abstract}
:
Neosporan eksponencijalni rast primene Interneta u savremenom bankarskom i berzanskom poslovanju predstavlja osnovni trend $\mathrm{u}$ finansijskoj industriji koji povratno daje zamah razvoju novih tehnologija. Internet kao osnova elektronskog bankarskog i berzanskog poslovanja omogućava veću diversifikaciju načina na koje se pristupa bankarskim i berzanskim uslugama, niže troškove obrade transakcija, veći komfor, lakšu i transparentniju komunikaciju finansijskih posrednika i njihovih klijenata, lakši i brži uvid u obavljene transakcije i stanje na računima. Primena Interneta $\mathrm{u}$ finansijskoj industriji se generalno može posmatrati kroz primenu $\mathrm{u}$ tri velike oblasti: bankarstvu, bezgotovinskom plaćanju i berzanskom poslovanju. U bankarstvu se uloga Interneta može sagledati kroz primenu u e bankingu, home bankingu, mobilnom bankarstvu, bankomatima i POS terminalima. U obavljanju finansijskih bezgotovinskih transakcija uloga Interneta je nezaobilazna kod platnih kartica (debitnih, kreditnih i poslovnih) i unapređenih smart varijanti tj. pametnih kartica, elektronskih novčanika, elektronskog novca koji može biti centralizovan (PayPal, Strajp, WebMoney, Payoneer) i ne centralizovan (Bitcoin, Litecoin), kao i kod sistema mikroplaćanja (Micropayment). U berzanskom poslovanju uloga Interneta je nezaobilazna u poslovanju i izvršavanju transakcija na finansijskim i robnim berzama kao i na Forex tržištu, jer različite elektronske trgovačke platforme počivaju upravo na Internetu.
\end{abstract}

\section{Key words:}

e banking,

home banking,

elektronski novac;

Forex,

meta trader.

\section{UVOD}

Razvojem informacione i telekomunikacione tehnologije stvoreni su uslovi za globalizaciju poslovanja. Razvoj Interneta i umrežavanje pojedinaca, preduzeća i javne administracije dovode do bitnih promena u načinu i efikasnosti rada poslovnih sistema. Imperativ savremenog poslovanja je postao da se bez obzira na geografsku udaljenost, što brže i efikasnije povežu klijenti i tokovi informacija. Razvojem elektronskog prenosa sredstava, finansijski instrumenti i tehnologija poslovanja su se znatno promenili. Finansijske transakcije se prenose na neograničenu udaljenost u realnom vremenu putem postojećih komunikacionih mreža zasnovanih na Internetu, bez tradicionalnog pripremanja naloga i prateće dokumentacije. Elektronsko bankarstvo, bezgotovinska plaćanja i savremeno berzansko poslovanje su segmenti koji su transformisani od klasičnog načina rada i poslovne saradnje ka elektronskom poslovanju i digitalnoj ekonomiji.

\section{PRIMENA INTERNETA U BANKARSTVU}

Primena Interneta u bankarstvu se odnosi na podršku internim poslovnim procesima (intranet), na proces povezivanja poslovnih partnera (ekstranet), na globalizaciju poslovnih procesa i obavljanje složenih bankarskih transakcija korišćenjem Internet servisa. Savremeni novac je kreditni novac čije je kreiranje povezano sa odobravanjem kredita. Termin elektronski novac se poistovećuje sa terminom digitalni novac, mada ima i autora koji povlače granicu između ova dva termina, jer je elektronski novac stvorio preduslove za nastanak digitalnog novca, a danas se sve više preobražava u njega. Jedna od definicija razgraničenja ovih pojmova glasi:“Dok elektronski novac predstavlja širi koncept koji se odnosi na sve mehanizme za transfer novca bazirane na računarima kao i na odgovarajuću opremu za pristup ovim sistemima, digitalni novac predstavlja uži termin koji se odnosi na sisteme za transfer novca putem Interneta"[1]. 
Uticaj Interneta u bankarskom poslovanju se odslikava kroz e banking, home banking, mobilno bankarstvo, bankomate i POS terminale. E banking se odnosi na usluge koje banke pružaju svojim komitentima - privrednim subjektima prvenstveno u domenu domaćeg i inostranog platnog prometa. Dalji razvoj e bankinga je pod uticajem kombinacije rasta upotrebe Interneta i Web tehnologija sa trendovima ekonomske globalizacije i koncentracije finansijskih usluga. Internet kao komunikaciona platforma za poslovanje nudi univerzalnu povezanost i dodatne prednosti i potencijale za redukciju troškova. Jedna od prednosti je proširenje mogućnosti upotrebe e bankinga na sva preduzeća bez obzira na njihovu veličinu. Jedan od problema koji se prevazilazi je i odvojenost trgovinskih tokova i tokova plaćanja kroz koncept direktnog procesinga ili STP (Straight-Through-Processing). Ovaj koncept se bazira na ideji da se podaci samo jednom unose $u$ određenu bazu, a da se iz nje koriste prenosom za potrebe procesinga svih faza u proceduri elektronske trgovine. $\mathrm{Na}$ taj način se smanjivanjem broja unosa podataka i automatizacijom, dodatno povećava efikasnost i smanjuju greške i rizici. Banke su zakođe uočile da elektronskom distrubucijom dokumenata različitim tržišnim učesnicima mogu da skrate vreme transakcija i snize troškove. Otuda su razvijene nove finansijske solucije koje ubrzavaju automatizaciju tokova plaćanja i procese finansiranja međunarodne trgovine. Jedan od najznačajnijih projekata u toj oblasti poznat je pod nazivom BOLERO (Bills of Landing Electronic Registry Organization). On predstavlja novu finansijsku soluciju za automatizaciju tokova plaćanja i procese finansiranja trgovine elektronskim distribuiranjem finansijskih i robnih dokumenata (akreditiva, konosmana, menica i sl.) sa digitalnim potpisom, što skraćuje vreme njihove cirkulacije i snižava troškove transakcija u oblasti međunarodne trgovine koja je poznata kao skupa i obimna, logistički i vremenski neefikasna, sa visokim troškovima, velikim brojem finansijskih i robnih dokumenata.

Home banking ili kućno bankarstvo kao vid samouslužnog bankarstva nastalo je sa željom da se komitenti banke iz svojih stanova direktno uključe u elektronski transfer novca. Ovaj tip bankarstva omogućava neposredan transfer sredstava, informacija i naloga bez pisanja pratećih dokumenata. U osnovi on je evoluirao od upotrebe savremene telefonske mreže za transfer informacija i naloga i neposredno obavljanje finansijskih transkcija ka upotrebi kućnih personalnih računara tj. digitalizaciji zasnovanoj na upotrbi Interneta.

Pozivni centar (call centar) ili govorni sistem banke je jedna od tehnologija u bankarstvu koja se koristi da komitentima pruži mogućnost da pozivanjem banke dobiju niz informacija telefonom, bez kontakta sa službenicima banke.

Mobilno bankarstvo podrazumeva pružanje bankarskih usluga kao što su uvid u stanje na računima, istorija izvršenih transakcija, fotografisanje naloga i samo davanje naloga za plaćanje, obavljanje menjačkih poslova, praćenje klijenata dok su u pokretu, instant poruke, video konferencije i sl. putem mobilinih uređaja. Mobilni telefoni su se pokazali kao izvanredan kanal distribucije bankarskih proizvoda i usluga koji je integrisan sa ostalim kanalima preko kojih banke pružaju usluge. Mobilno bankarstvo vidno menja način na koji komitenti koriste bankarske usluge, jer pored mobilnosti i jednostavnosti, ono je za klijente banke do 50 puta jeftinije od klasičnog načina korišćenja bankarskih usluga vezanog za posete ekspoziturama.

Bankomati (ATM) ili samouslužni šalteri se koriste od strane banaka, orijentisanih prema klijentima, sa ciljem povećanja kvaliteta usluga. Te usluge se uglavnom odnose na rutinske bankarske operacije: podizanje gotovine, polaganje depozita, prenos sa računa na račun, plaćanja, naručivanje i primanje izveštaja itd. Bankomati efikasno zamenjuju šalterske službenike u bankama i smanjuju operativne troškove. U odnosu na instalisane funkcije, bankomati mogu da budu: keš bankomati, info bankomati, bankomati za menjačke poslove, za plaćanje računa, za deponovanje dnevnog pazara, bankomati za prodaju vrednosti (polisa osiguranja i sl.) i multifunkcionalni bankomati koji obavljaju više pomenutih funkcija istovremeno.

POS terminali služe za elektronski transfer sredstava na mestu prodaje (EFT/POS electronic funds transfer point of sale) pomoću instaliranih terminala u trgovačkoj i uslužnoj mreži. U firmama - komitentima banke terminali ili registar kase se povezuju sa bankarskom računarskom mrežom. Korisnici POS terminala su u mogućnosti da na mestu kupovine proizvoda ili usluga vrše plaćanje prenosom iznosa sa svog računa na račun prodavca.

\section{BEZGOTOVINSKA PLAĆANJA}

Plaćanje bez upotrebe gotovog novca ili bezgotovinsko plaćanje zauzima sve značajnije mesto u strukturi ukupnog plaćanja između učesnika u platnom prometu. Bezgotovinskim plaćanjem se smanjuje potreba izdavanja, čuvanja, prenošenja i čestog prebrojavanja enormnih količina gotovog novca. Najčešće korišćena sredstva za obavljanje finansijskih transakcija u bezgotovinskom poslovanju su: platne kartice (debitne, kreditne i poslovne), pametne kartice (Smart Card), elektronski novčanici (Electronic Wallet), elektronski novac koji može biti centralizovan (PayPal, Strajp, WebMoney, Payoneer) ili necentalizovan (Bitcoin, Litecoin) i sistem mikroplaćanja (Micropayment).

Platne kartice su instrumenti bezgotovinskog plaćanja koji se koriste za identifikaciju izdavaoca i korisnika kartice na aparatima za izvođenje finansijskih transakcija. Platne kartice su sredstvo plaćanja dok su debitna, kreditna i poslovna kartica njene podvrste. Platne kartice se nazivaju i „plastičnim novcem“ jer zamenjuju čekove i gotovinu, tako što se plaćanja putem ovih kartica vrše na teret računa otvorenih kod banaka. Kada se koristi debitna kartica, na računu u banci mora imati novca koji se želi potrošiti. Kod kreditnih kartica je suprotno. Na računu nema novca koji se troši, već se na kraju obračunskog perioda (meseca ili nekog drugog određenog perioda) plaća iznos koji je potrošen u potpunosti ili delimično (na rate) sa pripadajućom kamatom za konkretan kreditni period. Poslovna kartica je vezana za one vrste troškova zaposlenih u preduzeću koji nastaju u procesu obavljanja radnih zadataka, a koji su unapred određeni aktima preduzeća. 
U zavisnosti od vrste aranžmana između preduzeća i banke, poslovne kartice mogu da imaju karakter debitnih ili kreditnih kartica. Upotrebom platnih kartica kao bezgotovinskog načina plaćanja ubrzava se tok finansijskih sredstava i smanjuju troškovi naplate. Otklanja se potreba za klasičnim fakturisanjem što značajno snižava tehničke i administrativne troškove same naplate, a samom kupcu pruža uvećan komfor koji je karakterističan za bezgotovinska plaćanja putem Interneta.

Smart ili pametne kartice u sebi sadrže integrisano kolo ili čip na kom se nalazi procesor i memorija. Na čipu se mogu čuvati određeni podaci na siguran način. Atraktivnost tehnologije pametnih kartica leži u raznovrsnosti mogućih primena. Na smart kartici se mogu razviti raznovrsne aplikacije u oblastima kao što su digitalni potpis, kupovina, zaštita autorskih prava, elektronska kupovina i sl. U zavisnosti od vrste ugrađenog čipa, smart kartice mogu biti memorijske, procesorske ili kombinovane, a postoje i bezkontaktne pametne kartice koje imaju minijaturnu antenu putem koje se bežično mogu slati i primati informacije u bežičnoj komunikacionoj mreži. U poređenju sa konvencionalnim platnim karticama, smart kartice imaju značajne prednosti na području sigurnosti, komfora pri korišćenju, ekonomskih efekata, prilagodljivosti posebnim potrebama i multifunkcionalnosti.

Digitalni novac u formi „elektronskog novčanika“ (Electronic Wallet) bazira se na prethodno izvršenim uplatama monetarne vrednosti, koje su registrovane na mikročipu elektronske kartice i mogu se upotrebiti za plaćanja roba i usluga. Suština funkcionisanja digitalnih novčanika leži u činjenici da se određena količina realnog novca konvertuje u elektronski novac koji se nesmetano koristi za plaćanje roba i usluga, pre svega online tj. na i Internetu. Korisniku omogućava da sa samo jednim klikom na bilo kom Web sajtu potvrdi svoj identitet i plati nešto što želi da kupi. Na taj način ova usluga ubrzava proces naručivanja i plaćanja roba i usluga i smanjuje rizik različitih zloupotreba.

Dve osnovne kategorije digitalnih novčanika su: Client-based digitalni novčanik (digitalni novčanik smešten na desktop-u klijenta) i Server-based digitalni novčanik (digitalni novčanik smešten na udaljenom serveru) [2].

Kao što su pojava i razvoj papirnog novca pokazali da i papirne novčanice, kao surogat novca, čija je vrednost praktično zanemarljiva, mogu vršiti sve funkcije valutnog novca ako za njih neko garantuje, tako je i pojava digitalnog novca razbila iluzije o neophodnosti opipljivog fizičkog medijuma (papira, metala) za funkcionisanje novca. Umesto da se informacija smešta na neki fizički medijum, ona se može upakovati u niz cifara koji će se kretati računarskim mrežama u elektronskom obliku i razmenjivati za proizvode i usluge.

Do sada razvijeni koncepti digitalnog novca mogu biti centralizovani (PayPal, Strajp, WebMoney, Payoneer) koji prodaju svoju elektronsku valutu direktno krajnjem korisniku i koriste se najčešće za online transakcije ili necentalizovani (Bitcoin, Litecoin) koji se zasnivaju na monetarnom sistemu unutar mreže.
Sistem PayPal je omogućava da se uplate i novčani prenosi obavljaju u potpunosti preko Interneta. PayPal je vrsta P2P (klijent-klijentu) usluge na način koji omogućava bilo kome ko ima e mail adresu da pošalje novac nekom drugom ko takođe ima e mail adresu. Inicijator transakcije preko PayPala se prvo mora registrovati na PayPal stranicama, a zatim prebaciti određenu svotu novca na svoj korisnički račun. Novac se može prebaciti direktno sa tekućeg računa u banci ili sa debitne ili kreditne kartice. Primalac PayPal transfera ima mogućnost da izabere nekoliko opcija: da zatraži ček od PayPala, da otvori svoj korisnički račun ili da zatraži prenos sredstava na svoj račun u banci. PayPal omogućava i plaćanja između dobavljača, aukcijskih stranica i drugih komercijalnih korisnika za šta se naplaćuje određena naknada u vidu jednog procentualnog dela od iznosa transakcijei jednog fiksnog dela po transakciji. Na taj način PayPal je tipičan primer posrednika u bezgotovinskom plaćanju koji olakšava i stimuliše svetsku Internet ekonomiju.

Najnovija konkurencija PayPal sistemu bezgotovinskog plaćanja predstavlja sistem Strajp koji preduzećima nudi obavljanje finansijskih transakcija preko Interneta. Potražnja za uslugama ovog tipa će u narednom periodu brzo rasti jer se trenutno preko Interneta obavlja samo $2 \%$ komercijalnih transakcija u svetu, a predpostavlja se da bi preko Interneta trebalo da se obavlja od 20 d0 40\% transakcija na makro osnovi.

WebMoney transferni sistem je nastao u Rusiji, a danas je prisutan u 86 zemalja, sa oko 22 miliona korisnika i sa desetinama hiljada prodajnih mesta koja prihvataju uplate putem ovog sistema. Sistem omogućava korisnicima Interneta da sprovode bezbedne transakcije u realnom vremenu koristeći WebMoney jedinice. WebMoney transakcije ne zahtevaju kreditne kartice ili bankarski račun, a transakcije su konačne i ne mogu se opozvati. WebMoney nije integrisan u međunarodni finansisjski sistem. On ne prihvata transfere WesternUniona i PayPala. Mnoge operacije na WebMoney su vezane za sistem poverenja i mogućnost prevare.

Payoneer je isplatna kompanija koja je registrovana kao član servisne provajderske mreže MasterCarda, sa sedištem u Njujorku i razvojnim centrom u Izraelu. Kompanija je finansirana kapitalom venture fondova.

Bitcoin je forma digitalne necentralizovane valute koja se nabavlja procesom data mining-a preko P2P mreže. Zarađeni (iskopani) novčići mogu se koristiti za plaćanje dobara ili usluga na Internetu, kao i za preprodaju. Cena samih novčića je dosta volatilna i varira u zavisnosti od stanja na tržištu. Broj sajtova koji primaju Bitcoin za naplatu konstantno raste. Sama budućnost Bitcoina je diskutabilna jer ga mnogi nazivaju novim tulip bubbleom. Regulatorni organi mnogih zemalja različito reaguju na Bitcoin. Kineska centralna banka je zabranila trgovinu i plaćanje Bitcoinom za finansijske institucije i druga pravna lica. Nemačko zakonodavstvo je zvanično priznalo Bitcoin način plaćanja, što ujedno znači i da ga je uvrstilo u zakonsku poresku obavezu i sankcije.

Do novčića Bitcoina se dolazi tako što računar rešava određene algoritme koji se kriju iza podataka, u nadi 
da se u nekom od njih nalaze novčići. Kako ne postoji Centralna banka koja bi regulisala vrednost individualnih novčića, njihova cena je regulisana samo ponudom i tražnjom i otuda proizilazi velika volatilnost vrednosti Bitcoina. Nepostojanje Centralne banke takođe prouzrokuje i problem nepostojanja kredita i kamata, što je neophodno da bi se Bitcoin mogao smatrati pravom valutom. Jedan od problema je što Bitcoin ne podleže državnim regulativama pa se njime na Internetu mogu kupovati proizvodi koji su u nekim zemljama ilegalni. S druge strane Bicoin je nemoguće falsifikovati, nije podložan poreskom sistemu domaćih tržišta, transakcije su relativno anonimne, a novčići se mogu menjati za razne valute i slati bilo gde na svetu u realnom vremenu, bez ikakvih troškova.

Litecoin je inspirisan i tehnički gotovo identičan Bitcoinu. On je takođe forma necentralizovane valute koja je programirana sa namerom da poboljša koncept Bitcoina, proširi pokrivenost tržišta i postane alternativa ili naslednik Bitcoinu. Postoje tri ključne razlike Litecoina u odnosu na Bitcoin, a to su da Litcoin mreža brže obrađuje blokove informacija, za šta joj je potrebno 2,5 minuta, dok je Bicoinu potrebno 10 minuta. Zatim Litecoin koristi scrypt u rešavanju algoritama, i na kraju Litecoin proizvodi četiri puta više novčanih jedinica nego Bitcoin mreža.

Micropayment, mikroplaćanja ili pikoplaćanja su sve prisutniji termini na Internetu. Mikroplaćanja su elektronska plaćanja male vrednosti koja su specijalno dizajnirana za elektronsku trgovinu na Internetu, pre svega za kupovinu dobara i usluga vrednih od nekoliko dolara do nekoliko centi, pa i manje (parking, prevoz, telefon, napici, kopiranje Internet sadržaja, lutrija, kocka itd.). Mikroplaćanje predstavlja zamenu za sitan novac uz odlike da je jeftin, elektronski je pokretljiv, lakši je za prebrojavanje, proveru i verifikovanje. Do sada je izrađen mali broj funkcionalnih sistema mikroplaćanja, a najpoznatiji među njima su MiliCent, SyberCoin i NetBill.

Karakteristika MiliCenta je da nudi anonimnost u plaćanjima. Kupac kupuje karticu sličnu telefonskoj i za vreme plaćanja razmenjuje deo novca sa brokerom $i$ vrši plaćanja, dok prodavac skuplja delove i razmenjuje za novac. Svako se može registrovati kao broker.

SyberCoin sistem se zasniva na računovodstvenom transferu odgovarajućih iznosa. Ovaj sistem vrši transfer novca sa potrošačevog privremenog računa na prodavčev privremeni račun, koji su, posebno za tu namenu, kreirani u SyberCash banci.

NetBill je sistem mikroplaćanja koji je koncipiran da ima ulogu treće strane koja vrši proveru autentičnosti, upravlja računima, vrši obradu transakcija, fakturisanje i informisanje klijenata i korisnika u mreži.

\section{BERZANSKO POSLOVANJE}

U berzanskom poslovanju uloga Interneta je nezaobilazna u poslovanju i izvršavanju transakcija kako na finansijskim i robnim berzama tako i na Forex tržištu, jer različite elektronske trgovačke platforme počivaju upravo na Internetu.
Meta Trader 4 je elektronska platforma za trgovanje koja je u širokoj upotrebi od strane online deviznih trgovaca. Ovaj softver je licenciran za devizne brokere koji pružaju softver za svoje klijente. On obezbeđuje trgovinske operacije, grafikone i tehničku analizu u realnom vremenu.

Unapređena verzija Meta Trader 5 je zamišljena kao platforma za tržišta deviza, ali i za tržišta kapitala, CFD-a i fučersa. Samo shvatanje i prihvatanje verzije 5 je sporo, tako da trenutno i dalje u upotrebi dominira trgovačka platforma Meta Trader 4. Obe platforme i Meta Trader 4 i 5 koriste prilagođene indikatore i trgovinske programe, tzv. „stručne savetnike“ za automatizaciju trgovanja.

Devizno tržište Forex je globalno decentralizovano tržište za trgovanje valutama. Glavni učesnici na ovom tržištu su velike međunarodne banke (tabela 1). Devizno tržište pomaže međunarodnu trgovinu i investicije omogućavajući konverziju valuta. On podržava i direktne spekulacije u vrednosti valuta, a takođe i carry trade - spekulacije bazirane na razlici između kamatnih stopa dve valute. Obim Forex trgovanja beleži konstantan i ubrzan rast. Prosečno dnevno trgovanje na Forex tržištu je iznosilo u aprilu 2007, aprilu 2010, i aprilu 2013. godine 3,3 biliona USD, 4,0 biliona USD i 5,3 biliona USD respektivno.

Tabela 110 najvećih trgovaca devizama na svetu

\begin{tabular}{|c|c|c|}
\hline \multicolumn{3}{|c|}{$\begin{array}{l}\text { Top } 10 \text { currency traders } \\
\% \text { of overall volume, May } 2013\end{array}$} \\
\hline Rank & Name & $\begin{array}{c}\text { Market } \\
\text { share }\end{array}$ \\
\hline 1 & Deutsche Bank & $15.18 \%$ \\
\hline 2 & 䊦 Citi & $14.90 \%$ \\
\hline 3 & Barclays Investment Bank & $10.24 \%$ \\
\hline 4 & $+\underline{\mathrm{UBS} A G}$ & $10.11 \%$ \\
\hline 5 & 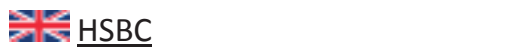 & $6.93 \%$ \\
\hline 6 & 握 JPMorgan & $6.07 \%$ \\
\hline 7 & Royal Bank of Scotland & $5.62 \%$ \\
\hline 8 & + Credit Suisse & $3.70 \%$ \\
\hline 9 & 恝 Morgan Stanley & $3.15 \%$ \\
\hline 10 & 恝 Bank of America Merrill Lynch & $3.08 \%$ \\
\hline
\end{tabular}

Izvor: Euromoney FX survey 2013.

Na ukupnom svetskom deviznom tržištu u 2012. godini, po vrednosti, najviše se trgovalo američkom dolarom, evrom, japanskim jenom, funtom itd. kao što je prikaza- 
no u tabeli 2, gde je data kompletna valutna distribucija prometa globalnog deviznog tržišta. Ukupan zbir je 200\% zbog toga što svaka valuta kojom se trguje uvek uključuje valutni par.

Ttabela 2 najtrgovanije valute na svetu

Most traded currencies by value

Currency distribution of global foreign exchange market turnover

\begin{tabular}{|c|c|c|c|}
\hline Rank & Currency & 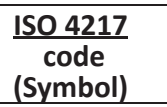 & $\begin{array}{l}\text { \% daily share } \\
\text { (April 2013) }\end{array}$ \\
\hline 1 & 些 United States dollar & USD (\$) & $87.0 \%$ \\
\hline 2 & Euro & $\operatorname{EUR}(€)$ & $33.4 \%$ \\
\hline 3 & - Japanese yen & JPY (¥) & $23.0 \%$ \\
\hline 4 & Pound sterling & $\operatorname{GBP}(f)$ & $11.8 \%$ \\
\hline 5 & Australian dollar & AUD (\$) & $8.6 \%$ \\
\hline 6 & + Swiss franc & $\mathrm{CHF}(\mathrm{Fr})$ & $5.2 \%$ \\
\hline 7 & $\$$ Canadian dollar & CAD (\$) & $4.6 \%$ \\
\hline 8 & Mexican peso & MXN (\$) & $2.5 \%$ \\
\hline 9 & Chinese yuan & CNY (¥) & $2.2 \%$ \\
\hline 10 & New Zealand dollar & NZD (\$) & $2.0 \%$ \\
\hline 11 & Swedish krona & SEK (kr) & $1.8 \%$ \\
\hline 12 & Russian ruble & RUB & $1.6 \%$ \\
\hline 13 & th Hong Kong dollar & HKD (\$) & $1.4 \%$ \\
\hline 14 & Singapore dollar & SGD (\$) & $1.4 \%$ \\
\hline 15 & C. Turkish lira & TRY (も) & $1.3 \%$ \\
\hline \multicolumn{3}{|r|}{ Other } & $12.2 \%$ \\
\hline \multicolumn{3}{|r|}{ Total } & $200 \%$ \\
\hline
\end{tabular}

Izvor: http://www.investopedia.com:"World's Most Traded Currencies By Value 2012“, poseta 10.06.2013.

Berze pružaju usluge berzanskim posrednicima i trgovcima koji trguju akcijama, obveznicama, finansijskim derivatima i drugim hartijama od vrednosti. Berze pružaju uslove za izdavanje hartija od vrednosti i za njihovo sekundarno trgovanje. Danas je trgovanje na berzi sve manje povezano sa fizičkom lokacijom berze, jer berze sada predstavljaju moderna tržišta elektronskih mreža koje putem Interneta povezuju sve tačke na planeti, pa je na svakoj berzi moguće, preko ovlašćenih članova berze, trgovati iz najrazličitijih delova sveta u realnom vremenu, što povećava brzinu i smanuje troškove transakcija.

OTC tržišta ili Over the Counter (preko šaltera) tržišta su vanberzanska tržišta na kojma se trguje nelistiranim hartijama od vrednosti, direktno između dve strane i to kako akcijama tako i obveznicama i derivatima (robni, finansijski, kamatni, devizni) - fjučersima i opcijama. Ona su takođe povezana elektronskim mrežama putem Interneta. Njihov ubrzani razvoj upravo i počiva na primeni elektronskih platformi i Interneta u poslovanju.

\section{ZAKLJUČAK}

Primena savremenih naučnih dostignuća u finansijskom poslovanju oličenih u primeni telekomunikacionih tehnologija i Interneta u bankarskom i berzanskom poslovanju predstavljaju osnovni trend razvoja finansijske industrije poslednjih decenija. Razvoj raznovrsnih načina izvođenja finansijskih transakcija upotrebom informacione i telekomunikacione tehnologije bazirne na primeni Interneta smanjuje troškove transakcija, obezbeđuje brži obrt sredstava, siguran i bezbedan platni promet, uštedu vremena i mogućnost obavljanja finansijskih transakcija sa bilo kog mesta na svetu gde je dostupan Internet. Primena Interneta u finansijskoj industriji dominira u oblasti bankarstva, bezgotovinskog plaćanja i berzanskog poslovanja. Ne samo da savremena tehnička i naučna dostignuća podstiču primenu Interneta u finansijskom poslovanju, već i sam Internet podstiče i omogućava brz naučni i tehnološki razvoj, pri čemu su pozitivni uticaji obostrani.

\section{LITERATURA}

[1] D. Ćosić, M. Bogavac, "Elektronsko poslovanje i baze podataka," Univerzitet Union, Beograd, 2012., pp.166.

[2] V. Simović, "Elektronsko poslovanje," Visoka škola strukovinh studija za informacione tehnologije, Beograd, 2011, pp.154.

[3] J. Seity, "Internet Banking - an Overview, " Journal of Internet Banking and Commerce, Ottawa, Canada, Vol 3, No 1, 2003.

[4] M. Hadžić, "Bankarstvo," Univerzitet Singidunum, Beograd, 2013.

[5] R. Stankić, "Elektronsko poslovanje," Ekonomski fakultet u Beogradu, Beograd, 2009.

[6] www.bloomberg.com

[7] www.euromoney.com

[8] www.investopedia.com

[9] www.forexfactory.com

[10] www.finviz.com 
THE ADVANTAGES OF USING E-BUSINESS IN ENTREPRENEURIAL ORGANIZATIONS

\begin{abstract}
:
Undeniable exponential growth in use of the Internet in modern banking and stock exchange business activities is the main trend in the financial industry who turn gives impetus to the development of new technologies. Internet as the basis for electronic banking and stock market operations allows for greater diversification of the ways in which access to banking and stock exchange services, lower cost of transaction processing, more comfort, easier and more transparent communication of financial intermediaries and their clients, easier and faster access to completed transactions and balances. The use of the Internet in the financial industry in general can be seen through the implementation of three major areas: banking, non-cash payments and stock exchange activities. In banking, the role of the Internet can be seen through the use of e banking, home banking, mobile banking, ATMs and POS terminals . The financial performance of non-cash transactions role of the Internet is indispensable in payment cards (debit , credit and commercial) and improved varieties known as smart cards, electronic wallets, electronic money that can be centralized (PayPal, WebMoney, Payoneer) and no centralized (Bitcoin, Litecoin), as well as micropayments system (micropayment). The stock exchange activities of the role of the Internet is indispensable in the business and executing transactions in the financial and commodity markets and the Forex market, as different electronic trading platform is based precisely on the internet.
\end{abstract}

Key words:

e banking, home banking, electronic money, Forex, meta trade. 